\title{
Considerations on foreign prostitution in Italy. A background picture
}

\section{Francesco Carchedi}

PARSEC. Associazione Ricerca e Interventi Sociali

Piazza O. Marucchi, 5. 00162 Roma. Italia

carfra@flashnet.it

\begin{abstract}
This study shows a descriptive work on the rellevance of foreign prostitution in Italy in the last years. It starts by addressing the various admission phases into prostitution and quantitative data on the issue. Secondly, it covers the definition and the typologies of foreign female prostitution. Thirdly, it addresses the ways of quitting prostitution and the future prospects of social intervention in this field.
\end{abstract}

Key words: prostitution, female immigration, Italy, women slave trade, prostitution typologies.

Resumen. Consideraciones acerca de la prostitución en Italia. Contexto de partida

Este estudio muestra un trabajo descriptivo sobre la importancia de la prostitución extranjera en Italia durante los últimos años. Comienza distinguiendo las diferentes formas de entrada a la prostitución, así como los datos cuantitativos sobre su presencia. En segundo lugar, cubre también la definición y las tipologías de la prostitución de las mujeres extranjeras. En tercer lugar, trata las vías para salir de la prostitución y las perspectivas de futuro en la acción social en este campo.

Palabras clave: prostitución, inmigración femenina, Italia, trata de blancas, tipologías de la prostitución.

\section{Summary}

1. Introduction

2. The various admission phases

3. How many and where are they?

4. Slave trade. Cues for a definition

5. Typologies in the practice

of prostitution
6. Ways of quitting

7. Brief conclusions

References 


\section{Introduction ${ }^{1}$}

«Merlin's Act» (of February 1958) deeply influenced the evolution of the phenomenon, decriminalising the crime of practising private prostitution. In fact in the sixties and seventies prostitution practised by Italian women, suffered a long irreversible transformation. From the «brothels» they found themselves on the streets and from the streets to private houses. In the eighties, other types stalked the streets, i.e. the drug addicts; and towards the end of the decade foreign women. In short, we can affirm that the first appear to be decreasing numerically, whilst the second, even though in a discreet manner, are increasing.

This last phenomenon has to be placed in the new configuration of the Italian society, that is, from the phase of an emigration country to a country of immigrants. It came in the seventies, the time, when the major North European countries with an old history of immigration put a stop to it, in 1972-73, when the effects of social transformation following the "economic boom» of the former decade became evident. The end of immigration policies were and continue to be expressions of border policies that is, they aim to stop or at least filter, the incoming migratory flows on the basis of precise clauses of no entrance.

These policies — amongst other things — have diverted a part of the migratory components, already bent towards migrating, in the direction of those countries where these laws did not exist and where the national labour markets asked for unskilled manpower. That is the European countries in the south of the Mediterranean basin, Italy (in the first place, since the first half of the seventies) Spain and Portugal (from the second half of the eighties) and Greece (from the beginning of the nineties). These countries — of the new immigration - are aligning with the stop policy promulgated twenty years earlier by the North European countries. The barrier of free circulation (for example among countries with ex-colonial connections), the interruption of the treaty on manpower (in general between the Northern and Southern Europe including also the Non EEC Countries) have in fact obliged, those who were already willing to emigrate to follow illegal ways of entrance, most often those covered by criminal organisations.

In practice, the necessity to migrate for work motives has been intercepted by these criminal organisations, because of the non-existent rules of entrance, therefore triggering a vicious circle of migratory flows, illegal emigration and precarious and uncertain settlements (at times very degrading) in the destination countries. Within this mechanism lies also foreign prostitution (and women slave trade), practised consciously and willingly (or at least wilfully chosen by the persons involved) or else coerced, i.e. against their personal will.

1. The following work is the synthetical result of an empirical research developed within the DAFNE Program of the European Commission in which participated: Dipartimento per le Pari Opportunità, Presidenza del Consiglio dei Ministri; the University of Florence; the University of Dundee, Diotima of Athens; the cooperative Parsec Servizi; the Municipality of Madrid; the Municipality of Bologna and the International Organisation of Migrations. 


\section{The various admission phases}

The presence of girls who enter prostitution is socially visible in Italy at the beginning of the nineties and goes on, in various phases in the years to follow. These phases correspond to small waves of flows characterised by the different nationalities, which arrived together with the bigger migratory waves - which came in regularly or irregularly conditions or situation - to the national territory in the last decade.

The first influx can be identified in 1989/90: that is because these were the years of major immigration from East to West (as a result of the fall of the Berlin Wall and the consequent opening of frontiers); it was also due to war in the ex-Yugoslavia with the aftermath of thousands of homeless and refugees seeking asylum; and also because of the passing of a law in Italy, regulating the presence of immigrants which — as it is well known - produced a significant attractive effect (Law n. 39/90, better known as «Legge Martelli»).

This first wave is characterised for its magma that makes it difficult to define in a specific manner the various nationalities of groups who practice (spontaneously or against their will) prostitution. It was in this period when «Polish girls» emerged, even though it more correctly denoted the women coming from Eastern Europe. In fact, even the Hungarians were called «Polish» notwithstanding the fact that their presence dated years back, together with the Brazilian women and Brazilian transsexuals.

The second wave - defined more from the point of view of nationalityis that of the Nigerian girls and, in a lesser manner, that of the Peruvians. These girls are regularly admitted in the country with a tourist visa. Once expired, they keep on staying in Italy in a non-regular manner. It is most likely that this second immigration quota, included within it segments of «traded women» i.e. deceived with malice and forced to prostitution, especially among Nigerians.

The third influx - better defined from the point of view of the main nationality, Albanian girls, characterised the 93-94 biennium. These women who had entered the country in a clandestine manner were mostly coming from big Albanian cities, who arrived together with their boyfriends or male relatives. Even in these cases the initial trick (specially played by friends with no scruples) carries out an important prostitution function. Today we know that prostitution revenues were invested in «financial pyramids» covered by the Government of Ex-President Berisha, who, in his turn, supplied other illegal trades.

The fourth influx discovered in the last two years, that is, at the beginning of 1995 was characterised by the arrival of women from Albania and Nigeria, aware that, once in Italy, they would have to work as prostitutes to pay the debt contracted at the time of their departure. What they did not know were the conditions of violent and aggressive exploitation, which did not allow them any possibility to ever absolve the signed contract. As a consequence, this determines the protracted nature of this subordinate relationship which ties them to their pimps and determines the methods of exploitation. At this stage we 
even find a change relating to the original areas of the origin of the girls. They are actually coming not only from big urban cities (as in the other arrivals) but also from little inner rural villages. This makes us think of a readjustment in the recruitment strategies by the traffickers, so much so that most probably in the big cities the game is well known and so it is too risky for their transnational business.

We identified a fifth influx starting at the beginning of 1996 through the first six months of 1998. It is characterised by a massive intervention of the police against groups of girls that were prostitutes for a long time (Nigerians and above all Albanians). At the same time, groups of girls coming from Russia, Moldavia, Lithuania, Romania were forced, with coercive methods, to work as prostitutes. This phase is characterised by the fact that small groups of girls, in particular Nigerians and ex-Russian citizens, are brought to the cities in the South, at first in the area round Naples and then in those of Catania and Bari.

The irregular methods of admission were both similar, in part, to those of immigrant worker flows, and different in some aspects. They are the same in as much as the girls/women are tricked, and exploitation and coercion begin immediately on their arrival in the country of settlement. Otherwise they are different when the girls/women destined to prostitution have been kidnapped, and so their transport from where they have been trapped to the country where they would practice prostitution is conducted in a very discreet and secret manner.

\section{How many and where are they?}

\section{Official figures}

The «Merlin Act» (n. 75/58) has depenalized the crime related to the practice of prostitution, when this is practised privately, and in turn it aggravates all the illegal activities yielding from it. For these reasons, also characterised by a deep sense of civility, it remains almost impossible to define statistically this phenomenon. Judicial statistics highlight only crimes for «instigation, exploitation, and abetting prostitution", that is, those crimes which are committed collaterally to prostitution but which are not chargeable to those who practice prostitution itself.

From this point of view, the number of persons who have been denounced (the majority being males) for the above mentioned crimes, rise from 327 in 1990 to 967 in 1995, that is evident, in the course of the quinquennium denunciations triplicated. The reasons for such an expansion can be various:

- a greater safety and quest for autonomy and freedom in those who practice the profession towards those who benefit by exploiting them;

- a wider territorial control by the police force and the presence of women agents who facilitate contacts with the «victims» (consequence of the merging of exploitation practices); 
- the presence of non-profit organisations that intervene in the sector and spread hope among the girls of ways of quitting the prostitution circuit, and

- the phenomenon spreads resulting in the large number of accusations, statistically speaking.

These are all credible hypothesis, but none of them alone satisfies completely the quantitative extension of the denunciations, even though all together they can offer a range of various explications.

In 1994 the accused subjects — subdivided by Region and nationalitywere 737 with highest points in Lombardy (134), Lazio (107) and Piedmont (71). On a total of 258 citizens (equivalent to a third) were foreigners, in particular Albanians (70), ex-Yugoslavs (65) and Nigerians (12). Obviously -as most of the statistics of juridical nature- one can make a comparison to the denounced crimes or the ones which the police catch in the act and so gives way to the "proper action» (denunciation or arrest). That is why the data and the official information offer a picture of comparison which is below the real figures in respect to the reality of violence and practices of hidden exploitation around the women (and even males) who practice prostitution.

\section{The national numerical value}

If on the one hand the official data tends to underestimate the phenomenon, on the other hand the procedures for estimation of the whole universe start to produce very early results on the components of immigration. We must, therefore, explain in detail that the practice of prostitution in private circles, as mentioned before, does not fall under the punishable crimes. In fact, let's suppose that for each denounced crime corresponds a person who practices prostitution, and thus we have a total corresponding to the number of accusations (that is 3,000 persons in the years 90-94, with the exception that the same people appear in the count more than once, in the same year or successive ones).

On the contrary, for foreigners, other correlated factors play a part: it could be defined as the "citizen effect». It is the lack or reduction of the full social fitness, as well as the presence of obstacles and forms of resistance of various nature, which hold up and slow down possible processes of social insertion. For example: the residence permit, the permanent address, the social protection networks, the access to services, the knowledge of resources and social dynamics, the division of the working time practising prostitution and the time spent camouflaged in society. In fact, it is basically the difficulty of determining estimation and the strong mobility which characterises the prostitutes. Actually, next to the groups which remain tied to their usual «residence», we have seen other groups which move from one territory to another following work opportunities.

The estimates show the numerical consistency related to 96 and 98 on a national level. As one can possibly see — according to these figures - the phe- 
nomenon was around 18,800 and 25,100 in 1996 and after further studies it results in a minor decrease, from 15,000 and 19,000 in 1998. This decrease reflects a better estimate calculated in the northern as well as in the southern regions. The latter, in particular, not having been subject to specific investigations in 1996, were grouped (and therefore estimated) together with other non-researched central/northern regions. Therefore, by treating them in the same procedure they were overestimated by at least a third (they actually switch from 5,000/6,800 in 1996 to 1,400/2,100 in 1998).

As regards other geographical areas — in the two years considered- the major presences are those concentrated in the north with figures around 7,700 to 11,300 followed by the centre with 5,600/7,000 Even in the north we find slight decreases, relative to the estimations of 1998, whilst in the centre - for the particular presence in the Rome area - the numerical consistencies seem to remain unchanged. The different weight of the presence of girls who practice prostitution in different geographical areas is actually explainable, one could suggest that the traditional social control —in its most widest meaning - is more significant in the south with respect to centralnorth.

This aspect leads to a wider predisposition to marriage and the formation of family groups at a younger age compared to those in other geographical areas where, among other things, one tends to remain in the family till the age of thirty and beyond, with the consequent limited behaviour. It results that these different behaviours aim (at least in this historical stage) to reduce, in the first case, paid sex, whilst, as a consequence, tends to a growth in the second one. This does not mean that where there is a family there is less need for paid sex, but that the process of modernisation, although necessary, can produce forms of individualism and of exasperated non-communication between males and females. The caesura that determines important distortions in the male/female relationships — not only among singles but also in the married ones - is related to a consequent existential and emotional strangement of both sexes.

The regions with a higher number of foreign girls who practice prostitution are Lazio and Lombardia, respectively, with 4,000/5,000 and 3,500/4,500 estimated units. They represent, on the other hand, the level of appearance of the immigration phenomena; the regions with a wider attraction for settlement, either for working opportunities in small enterprises and in the service activity, or else they represt for the opportunity of socialisation that big cities usually offer, in particular Rome and Milan. These cities seem to be - as a resultthose with a bigger number of prostitutes, and also as we have already said with a higher number of formal denunciations. As a whole, Rome and Milan actually reach, according to 1998 estimates, about a third of the total, as to the lower estimates $(5,000$ on about 14,715 units) and a little less of one fourth with regards to the maximum estimates $(9,500$ on 19,289).

Concerning the other regions - apart from Emilia Romagna and the Piedmont, respectively with 1,200/1,600 units estimated in 1998 - they are 
all below the 1,000 units, distributed on the outskirts of big cities and along the coastal resorts of higher tourist seasonal attraction (but even weekly).

\section{Slave Trade. Cues for a definition}

The difficulty in defining the concept of slave trade does not help to understand well the entity of the phenomenon, and to distinguish it from the mere practice of prostitution in all its various aspects. Actually, we can define the «slave trade» as that violent act committed by one or more persons (even in a coordinated continuous way in different national areas) against other persons, generally women and minors. The specific aim is to convince them to practice compulsory aspects of prostitution, i.e. to force them to have sexual encounters for money payment collected by a third party or the so-called pimps. In slave trade the concept of up rooting relates to a movement from the original country or from any other place voluntarily chosen as permanent residence.

From this angle, the traded women (traded or prostitutes being forced to) are substantially victims of kidnapping because of their resistance and opposition, and aversion towards the fulfillment of the action itself, on the one hand, and victims of slave trade, since they are uprooted coercively with the aim of inciting them to prostitution, on the other hand. It is the binomial kidnapping/sexual exploitation, which depicts the type of slave trade, in the presence of a coercive continued status, reducing the socioexistential fitness of those that are involved and snared. The slave trade also depicts a condition where freedom - in its positive and negative meaning - is reduced to the bare minimum and where the poor girls can be bought and sold to different groups of criminals and of a different nationality.

This condition of coercive violence can be determined in different places and in various phases: at the departure (stopping before the entrance in another country); at the entry of the country of settlement or in another country (stopping after some time or continuous in time), as well as during the stay in the country of settlement. For these reasons these microflows of people - apart from the typology characterised by the kidnapping, so coercion is absolute and to the maximum - can be camouflaged by the migratory flows in general; in as much as the concerned agree (sometimes for short trips) because they ignore what will happen to them once they arrive to destination.

The action's continuity presents a process which can start in the country of origin continuing at the entrance and during the stay in the country of settlement without any interruption, or else beginning and ending during each phase or in more phases with the involvement of one or more persons. However, depending on where it started we can find the original slave trade (starting from the country of provenance) and an induced slave trade (starting later). In the latter case, the condition of the traded woman is determined at a later stage, at the moment when an external violent and coercive action appears, which conditions her normal behaviour. 
Such a limitation comes from the so-called pimps (individuals or groups) who organise the sexual exploitation. In other words, we can affirm that we are assisting a slave trade when the coercive character of the relation is almost total (kidnapping), and is finalised with the coercive practice of prostitution. Paradoxically, the practice of prostitution by the girl determines, in time, the same conditions of the relation which is established with the so-called pimps. In as much as the interrelation dynamics amongst the actors involved can lead to a weakening of the coercive pressure and introduce elements of negotiation. These can remain in an embryonic state or else spread in a manner more or less convenient to the girls, as they can acquire a certain freedom in movement.

\section{Typologies in the practice of prostitution}

Living conditions for traded women —in its general aspects - are grouped in three principal typologies, each of them are correlated:

- to the experience or lack of previous practices of prostitution, on their arrival in Italy and to the forms of consensus or degree of trickery, coercion and violence at the start of the emigratory project, as well as the amount of debt contracted and the modalities of repaying it;

- to the temporary duration (from the beginning of the first entrance) and to the different experimental phases which characterise it; or as a process in the strengthening of the subordinate relation (at a disadvantage to those concerned) or else as a progressive process of unhooking of the same (in this case to the advantage of the concerned);

- to the modalities and levels of autonomy which the concerned succeed in acquiring or reach in practising the profession in agreement or with a certain equilibrium in the roles and functions of each partner, or in a clear or hidden contrast with the "pimps».

The three typologies, therefore, whenever the variables cited above perform a joint function, are those recognised in the practice of the profession in apartments (that is the "call girls») in private or public premises. This is the masked prostitution, for example the «entertainers», the «dancers» or the «porno actresses» or on the sidewalk («street walkers»). They are, however, recognised — starting from these- mixed typologies characterised from the possible combinations which can be produced by the distinctive aspects and modalities of one or the other or viceversa. Their living conditions vary according to the various positions the girls who practice prostitution have in the general typologies and these are also distinguished by national origin.

The practice of prostitution as a "call girl» is characterised by a prominent decisive independence of the person, by the decision in organising logistically (district, prices, routes and movement), as well as by the medical and legal stay in the country — permissions and certificates_- and also by the nature in the relations with the pimp. When there are pimps, they have the roles of 
friends or otherwise they are not in conflict or of violent subjection, because they are generally based on feelings and on a couple relationship.

The practice of the profession in a masked manner - that is, not of immediate visibility in as much very "protected» by another profession — is revealed in different ways. The most popular are: entertainers and dancers in public and private places (night clubs), beauticians and masseuses, stripteasers and actresses, as well as their extras working in pornovideos or as hostesses, entertainers and escort service.

In fact, the ways of life do not differ much from those of the "call girls", in terms of autonomy as to their physical appearance, to their relations with the pimps, and to the modalities in which they practice the job. The same thing can be seen by the presence of women who had the same job in the country of origin (work permit to these professionals is given without any difficulties).

The work of the street walkers is characterised by methods that differ a lot from those of the "call girls» or of the "masked ones», thanks to the strong social visibility that distinguishes it. Living and working conditions are often correlated in forms of general subordination. In the first place, to their "pimps»(with whom they often have personal and emotional relationships) and secondly — specially for some groups_ - living and working conditions are linked to criminal organisations, of the same nationality or Italian, with functional connections of a transnational character.

Among the «street walkers» the profession is generally carried out —in a more evident and direct manner - to reimburse the debt contracted with the international organisations which guarantee the expatriation, either when the girls are conscious (fully or partially) of what they have to do or when they are pushed to prostitution by coercive and violent methods.

In both cases, however, the prospect of prostitution becomes slowly — due to the violent pressures of the "pimps» — the quickest method to pay back the debt to the criminal organisation, triggering - without knowing - a mechanism destined to be taken forever, and in a way that differs a lot from what they had imagined. In the majority of the cases — as already mentioned — the pimps hold back the passports and other documents, such as the stay permit, or even threaten, not only the directly concerned, but also her relatives living in the native country. In short, it is often a very violent relationship that goes beyond all reasonable codes, to further flow into more or less evident forms of semi-slavery and psychophysical subjection of the girls/women involved.

\section{Ways of quitting}

The ways of quitting this vicious circle (i.e. violence on entry to in Italy, forced or tricked as a means to be pushed to exercise the profession, violence to perpetuate the activity) are based on some events which arise from different situations, depending on the various typologies.

In general, age plays a determining function in these women and therefore the time spent, if not the experience acquired by age, is the underlying 
«model» exercising the profession. In brief, the ways of quitting which emerge very clearly are the following:

a) Becoming maturer and being convinced in a completely spontaneous manner of the necessity to stop being a prostitute, notwithstanding the subjection and the violence endured by the pimps.

b) By the intervention of near relatives (and even friends) of the girls: either because the same girls have asked for help or because they themselves have come to know (directly or indirectly) of the conditions of life of their relatives. In both cases, however, the relatives/friends mobilise spontaneously or and this happens regularly — with the help of the police- with the aim to make them escape from this snare and this vicious circle in which they find themselves.

c) By the help of clients, with whom the girls manage to produce ways of solidarity and close relations. These ways of nearness succeed on one side to produce and slowly trigger off processes of support and disinterested attention to the conditions of the girls, and on the other side, to encourage them to take decisions with the aim of leaving the profession or at least to get rid of their pimps.

d) In the intervention by helpers from voluntary associations and by Service cooperatives directed to those women who suffer violence or who are in the condition of social marginality: operators who carry out their work on their own or in joined forces with the police.

e) With the intervention of the police force (with the presence of women agents) from the zone's police station and local police headquarters. They intervene for normal administrative inspections or on a specific request by the same girls. On other occasions, they intervene because the girls are found in a state of neglectness after enduring violence; because they find out that they are minors or without identification documents or else do not have the stay permit.

These various ways of quitting prostitution show, in short, the different offers of help which, at the moment, are verifiable inside this delicate and particular social sector. On the other hand, in this historical phase - where the phenomenon is clearly seen socially - the major structured interventions are those by the police, whilst the others - especially the third/voluntary sectorare still in an embryonic stage. The latter are in fact still at a first stage, even though they have increased in a decisive manner in the beginning of 1999, as a result of the official publication on foreign immigration (n 40/98) which sets in order amongst other things, the possibility of leaving the prostitution circle by girls/women for justice reasons (art. 18).

The cited law is trying to render the joint interventions of juridical outcomes (that is, those promoted by the police) and the social ones (promoted, on the contrary, by non-profit organisations accredited to work in the sector). This request by the non-profit organisations tends to equilibrate 
the two types of interventions in favour of the victim, in that, if the juridical one is too much ahead of the social, there is the risk that social welfare becomes more difficult.

In this case the phenomenon risks to perpetuate only as a field of repressive intervention, forgetting its more social components aimed, that is, on the figure of the snared, girls/women, who have to be treated differently with other philosophies and other instruments. In short, it means to find a way to exploit in a greater extent, social work and coordinate the efforts of all those who operate in the sector, spontaneously or in an organised way.

\section{Brief conclusions}

The phenomenon of foreign prostitution — springing from those countries where migration flows are also present - is a recent phenomenon and, at the same time, already mature, in such a way that is has the need of social intervention with strong commitments. One cannot think that this emergency will end in a few years. In Italy, it has been compared to the malignancy of the drug addiction phenomenon, which exploded in the beginning of the sixties and still, notwithstanding interventions of different nature and intensity, is very strong and widespread in society. The phenomenon of women slavery as a means of sexual exploitation is camouflaged, more in general, in the phenomena of prostitution, in the way that it portrays the more violent segment comparable to contemporary forms of slavery.

There is, therefore a need for economic funds and human capital trained specifically so that they can confront the phenomenon from more views: social, repressive and economical. The problem is to intervene on the collective who prostitute, intercept - when possible — the segment of traded women, and work with them with the aim to help them to reconstruct a way of life away from the prostitution circuits. Therefore, one possible way is to activate programmes of work insertion, even through formative courses, scholastic and professional. Another intervention, which is making way through the helpers in this sector, is that of being able to work with the organisations dealing with the areas of the formation of the prostitution flow (both spontaneous and coercive). Consequently, it means to experiment ways of cooperation with organisms and structures who work out interventions comparable to those conducted in the countries of settlement of the girls/women who prostitute themselves.

The validity of this approach to the problem — which we can define as two-sided - is based on the presumption that the foreign prostitution has reached a transnational dimension due to: geographical and territorial mobility - on rotation — which characterises some groups (for example, those from the East); as well as the means of conduction; the size and the articulation of the business to which they are associated (for example for the groups of Nigerians, Albanians and Latin Americans); and also the ways of exploitation which tend to be characterised more as those of multinational criminal organisations. 
In this ripe phase of the phenomenon two strategies are needed: one of a national character, related to the country of settlement, to lighten damages provoked on the people concerned and to promote mechanisms of quitting from the prostitutional circuits. The other, more of a transnational character, is referred to the country of origin; finalised to understand the causes from which the phenomenon springs and to activate the resources to contrast, remove or, at least, reduce and restrict them.

In other words, one must consider the phenomenon of prostitution as a symptom which interests the so-called migratory space, that is, that transnational space which any migrant of the first generation selfproduces towards the symbolic conjunction of the territories in which she/he has settled, her/his socioeconomic ability.

The girl/women who practices prostitution (forced or not) - like migrants - metaphorically assumes the resemblance of a two-faced Janus, who looks contemporary, to the birth country (where relative bonds are left too, where they send the money), as well as to the country of settlement (where they earn income, where they make new experiences).

\section{References}

AgEnZia ASPE (1995). «Prostituzione. Un mondo che attraversa il mondo 19831995». Rassegna Stampa. Periodici del gruppo Abele, Turin.

- (1996). "Prostituzione. Un mondo che attraversa il mondo». N. 18/19. Turin: ASPE.

AMBROSINI, M.; ZANDRINI, S. (a cura di ) (1996). «La tratta infame. La prostituzione delle donne straniere». Quaderni della Caritas. Milan.

Anthony, C. (1993). La prostittion clandestine. Paris: Le cherche Midi Editeur.

CAMPANI, G.; CARCHEdI, F.; PiCCIOlini, A. (1997). «Le trafic des femmes immigrées à des fins d'exploitation sexuelle en Italie». Migrations Société, n. 52. Paris: CIEMI.

Carcelli, G.; De Risi G. (1993). Prostituzione, droga, Aids: un'emergenza dal volto umano. Roma: Istituto Ricerche Economico Sociali Placido Martini (in collaborazione con la Croce Rossa Italiana e la Fondazione Vila Maraini).

COMITATO PER I DIRITTI CIVILI DELLE PROSTITUTE (a cura di) (1996). Progetto di informazione AIDS rivolto alle prostitutte immigrate. Relazione finale. Pordenone.

DA Pra POCCHIESA, M. (1999). «L'Italia delle opportunità. Prostituzione e tratta delle persone». Turin: Edizioni Gruppo Abele, n. 1.

De BARBES, Violette (1980). 50 ans de trottoir. Paris: Editions Alan Lefeuvre.

De STOOP, C. (1997). Trafficanti di donne. Turin: Edizioni Gruppo Abele.

Del Mundo, F. (1995). «Il traffico di vite umane». In: Rifugiati. Roma: Edizione ACNUR, October-December 1995.

Iglebaek, O. (1995). La Baltic connection. In: Rifugiati. Roma: Edizione ACNUR, October-December 1995.

International Organisation for Migration (IOM) (1994). Transit Migration in the Russian Federation. Budapest, 4 July, 1994.

- (1995). Trafficking and prostitution. The growing exploitation of migrant Women from central and eastern Europe. Budapest, May, 1995. 
Istituto NaZIOnALE di STATISTICA (ISTAT) (1994). Statistiche giudiziarie e penali. Anno 1994. Annuario n.3, Edizione 1995. Roma: Industria Poligrafica di Roma. LEONINI, L. (a cura di) (1999). «Sesso in acquisto». Milan: Edizioni Unicopli, Provincia di Milan.

Millet, K. (1975). Prostituzione. Turin: Einaudi.

O'GraY, R. (1995). Schiavi o bambini? Turin: Edizioni Gruppo Abele.

PARSEC; Università di FirenZe, Dipartimento di SCIENZE dell'EdUCAZIONE (1996). Il traffico di donne immigrate per sfruttamento sessuale: aspetti e problemi. Ricerca ed analisi della condizione italiana. Rapporto finale per la Conferenza Internazionale di Vienna. Organizzazione Internazionale delle Migrazioni, Rome, 1996.

SQUAdRone, G. (1996). «Carne umana: conta poco, rende tanto». Narcomafie, n. 4, anno IV, Torino.

TAMPEP (1996). Transnational AIDS/STD Preventing among migrant prostitutes in Europe Project. Final Report. June 1996.

TATAFIORE, R. (1994). Sesso al lavoro. Il rapporto. Milano. 